\title{
Depósitos funerarios de anfisbenios o "serpientes de dos cabezas" en la Plataforma Uhle, Huacas de Moche, Perú
}

\author{
Nicolas GOEPFERT \\ UMR 8096 « Archéologie des Amériques », CNRS, Paris I, \\ 21 allée de I'Université, F-92023 Nanterre cedex (France) \\ nicolas.goepfert@mae.u-paris10.fr
}

Salvador BAILON

UMR 7209 « Archéozoologie, Archéobotanique: sociétés, pratiques, environnements ", CNRS-MNHN,

55 rue Buffon, CP 55, F-75005 Paris (France) UMR 7194 « Histoire naturelle de l'Homme préhistorique », CNRS-MNHN,

1 rue René Panhard, F-75013 Paris (France) salvador.bailon@mnhn.fr

Christine LEFÈVRE

2 UMR 7209 « Archéozoologie, Archéobotanique: sociétés, pratiques, environnements ", CNRS-MNHN, 55 rue Buffon, CP 55, F-75005 Paris (France) lefevre@mnhn.fr

Belkys GUTIÉRREZ

Universidad Nacional de Trujillo, Trujillo (Perú)

belkysgl15@yahoo.es

Goepfer N., Bailon S., Lefèvre C. \& Gutiérrez B. 2013. - Depósitos funerarios de anfisbénidos o "serpientes de dos cabezas" en la Plataforma Uhle, Huacas de Moche, Perú. Anthropozoologica 48 (2): 487-505. http://dx.doi.org/10.5252/az2013n2a19

\section{RESUMEN}

Catorce especies animales fueron identificadas en las tumbas mochicas (100800 d.C.). Entre ellos, el descubrimiento de anfisbenios, un grupo de reptiles conocidos en América del Sur como «serpientes o culebras de dos cabezas», es un hallazgo nuevo. Restos de Amphisbaena sp., en particular $A$. occidentalis, la única especie actualmente presente en esta área, fueron encontrados en cinco tumbas de la Plataforma Uhle en el sitio Huacas de Moche. Esto constituye la primera mención de estos reptiles en sitios arqueológicos precolombinos de la vertiente occidental de la Cordillera de los Andes. Los anfisbénidos fueron descubiertos en cántaros colocados al lado de los muertos, lo que indica que eran depósitos intencionales y no vestigios intrusivos. Se conocen también ofrendas de anfisbénidos en el noroeste de Argentina, en la cultura 
PALABRAS CLAVES

Zooarqueología, Amphisbaena reptiles,

ritos funerarios cultura Mochica, Perú.
Ciénaga (2000-1400 BP), y durante los períodos de Desarrollo Regional, Inca e Hispano-Indígena (800-250 BP). Este tipo de depósitos no constituye un fenómeno cultural aislado, pero debe considerarse dentro de un contexto temporal y espacial más amplio. El registro iconográfico mochica aporta detalles adicionales y parece indicar que estos animales podrían tener un vínculo con la muerte y el sacrificio, pero también con la Vía Láctea. El descubrimiento de estos taxones ofrece nuevos datos para la comprensión de su papel ritual y de su función simbólica en las tumbas de la cultura Mochica.

\section{ABSTRACT \\ Amphisbaenids or "two-headed snakes" funerary deposits in the Uble Platform, Huacas de Moche, Peru.}

Fourteen animal species have been identified in Mochica tombs (100-800 A.D.). Among them the discovery of amphisbaenids, a group of reptiles known in South America as "culebras de dos cabezas" (two-headed snakes), stands as a new fact. Rests of Amphisbaena sp., in particular A. occidentalis, the only species actually present in this area, were found in five tombs of the Uhle's Platform at Huacas de Moche site. This constitutes the first occurrence of these reptiles in Precolumbian archaeological sites from the western slope of the Andean Cordillera. The amphisbaenids were discovered in jars sitting by the side of the dead, indicating that they were intentional deposits and not intrusive vestiges. Amphisbaenids offerings are also known in North-West Argentina, in the Ciénaga culture (2000-1400 BP), and during the periods of Regional Development, Inca and Hispano-Natives (800-250 $\mathrm{BP})$. This kind of offerings thus does not constitute an isolated cultural phenomenon, but should clearly be regarded within a wider temporal and space context. The Mochica iconographic register brings additional details and seems to indicate that these animals could have a link with death and sacrifice, but also with the Milky Way. The discovery of these taxa brings new data for understanding their ritual role and symbolic function in Mochica culture tombs.

\section{RÉSUMÉ}

Dépôts funéraires d'amphisbénidés ou "serpents à deux têtes" sur la plate-forme Uhle, Huacas de Moche, Pérou.

Quatorze espèces animales ont été identifiées dans les tombes mochicas (100800 apr. J.-C.). Parmi eux, la découverte d'amphisbénidés, un groupe de reptiles connue en Amérique du Sud comme «culebras de dos cabezas» (serpent à deux-têtes), se présente comme un fait nouveau. Les restes d'Amphisbaena sp., en particulier $A$. occidentalis, la seule espèce actuellement présente dans cette zone, ont été trouvés dans cinq tombes de la Plate-forme Uhle sur le site de Huacas de Moche. Ceci constitue la première occurrence de ces reptiles dans des sites archéologiques précolombiens du versant ouest de la Cordillère des Andes. Les amphisbénidés ont été découverts dans des jarres, déposées à côté des corps des morts, indiquant ainsi qu'il s'agissait de dépôts intentionnels et non de vestiges intrusifs. Les offrandes d'amphisbénidés sont également connues dans le nord-ouest de l'Argentine, dans la culture Ciénaga (2000-1400 BP), et pendant les périodes de Développement régional, Inca et Hispano-Indigène (800-250 BP). Ce type d'offrandes ne constitue donc pas un phénomène culturel isolé, mais doit clairement être considérée dans un 
MOTS CLÉS

Archéozoologie,

Amphisbaena,

reptile,

rites funéraires,

culture Mochica,

Pérou. contexte temporel et spatial plus large. Le registre iconographique Mochica apporte des détails supplémentaires et semble indiquer que ces animaux pourraient avoir un lien avec la mort et le sacrifice, mais aussi avec la Voie Lactée. La découverte de ces taxons apporte de nouvelles données pour la compréhension de leur rôle rituel et de leur fonction symbolique dans les tombes de la culture Mochica.
Los reptiles tienen un papel particular en las creencias religiosas de las poblaciones andinas. Están generalmente vinculados a la alternancia de las estaciones, a las lluvias, a la fertilidad y al mundo subterráneo. Sin embargo, su depósito ritual al interior de sepulturas prehispánicas es escaso. En este artículo, trataremos de un tipo especial de depósitos funerarios que constituye el descubrimiento de restos de anfisbenios dentro de vasijas depositadas en tumbas de la cultura Mochica de la costa norte del Perú. Nuestro enfoque se apoya sobre los datos arqueológicos y zooarqueológicos provenientes de las excavaciones de la Plataforma Uhle, así como sobre el estudio del registro iconográfico mochica. A partir de las fuentes etnohistóricas y de los testimonios etnográficos, veremos también que estos reptiles parecen haber jugado y juegan aún un papel simbólico.

\section{LA CULTURA MOCHICA, EL SITIO DE HUACAS DE MOCHE (HUACAS DEL SOL Y DE LA LUNA) Y LA PLATAFORMA UHLE}

La costa peruana es una larga banda desértica interrumpida periódicamente por ríos que nacen en los Andes. Estos ríos forman fértiles valles que fueron ocupados por poblaciones prehispánicas desde el Precerámico (Chauchat et al. 1992, 2006; Lavallée et al. 1999). La cultura Mochica o Moche fue una sociedad prehispánica que se desarrolló en la costa norte del Perú entre 100 y 800 d.C.. Se extendió entre los valles de Piura y Nepeña donde los Mochicas extendieron un importante sistema de riego que les permitió cultivar las tierras áridas de la costa (Fig. 1). Ellos construyeron grandes centros ceremoniales, cuyas pirámides de adobes son los testimonios más espectaculares. Los sitios mochicas se estructuraban alrededor de uno o varios edificios monumentales que incluían plataformas, zonas de viviendas y de artesanía, y que eran también utilizados para sus entierros.

El sitio arqueológico de Moche, llamado también Huacas de Moche, se conoce desde el siglo XVI y ha sido considerado por mucho tiempo como la capital de un estado mochica (Larco Hoyle 1938, 1939). Sin embargo, las investigaciones arqueológicas de las últimas tres décadas demuestran que los Mochicas estaban independientemente organizados por valles (Quilter \& Castillo 2010), y no como un estado centralizado, siendo la religión el vínculo cultural entre estas poblaciones (Donnan 2010). El asentamiento está ubicado en la margen izquierda del valle de Moche y se encuentra rodeado de tres conjuntos geomorfológicos: el río Moche al oeste, el Cerro Blanco - pequeño cerro de $500 \mathrm{~m}$ de altura - al este y el Cerro Negro al norte. Se extiende actualmente sobre una planicie arenosa de 40 ha y está rodeado de pequeñas parcelas agrícolas de la Campiña de Moche.

El conjunto arquitectónico está definido por dos pirámides monumentales: la Huaca del Sol y la Huaca de la Luna, y una importante zona habitacional y artesanal, la "Zona Urbana”. Gracias a los numerosos trabajos arqueológicos desarrollados en el sitio de Moche (Chapdelaine 2001; Chauchat et al. 2008; Donnan \& Mackey 1978; Uceda 2001), tenemos un mejor conocimiento de su ocupación, arquitectura, cronología y rituales (funerales, sacrificios humanos, etc.).

La Plataforma Uhle está ubicada al pie de la fachada oeste de la Huaca de Luna (Fig. 2) y debe su nombre a Max Uhle, el primer arqueólogo en realizar excavaciones en Moche entre 1899-1900 (Uhle 1913). Esta estructura mide $75 \mathrm{~m}$ de longitud por $25 \mathrm{~m}$ de ancho y fue excavada entre 1999 y 2009 por el Programa Internacional Moche, dirigido por C. Chauchat y B. Gutiérrez en colaboración con 


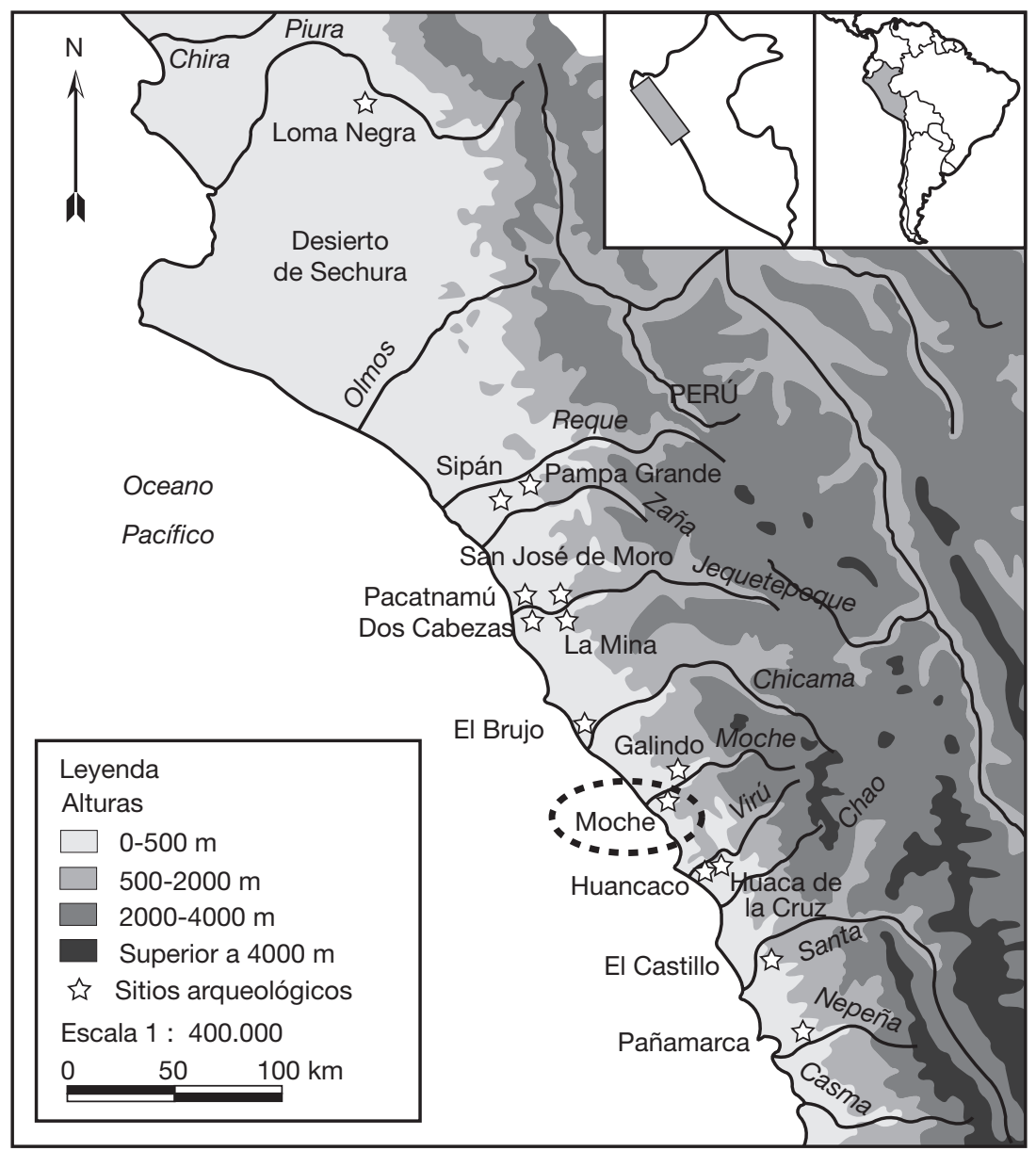

FIG. 1. - Mapa de localización del sitio de Moche (Huacas del Sol y de la Luna) y de los principales asentamientos mochicas.

los co-directores peruanos S. Uceda y R. Morales. Las excavaciones tuvieron como objetivo entender la naturaleza de su ocupación, su secuencia arquitectónica, encontrar una parte de la exploración de Max Uhle y analizar las sepulturas que se registraron durante las excavaciones (Chauchat 2000; Chauchat et al. 2008, 2009).

\section{LAS PRÁCTICAS FUNERARIAS MOCHICAS}

El estudio de las prácticas funerarias es un eje de investigación privilegiado sobre la cultura Mochica y numerosos trabajos fueron consagrados a ese tema (Castillo 2000; Donnan 1995; Donnan \& Mackey 1978; Millaire 2002). Los Mochicas enterraban a sus muertos en fosas, en cámaras funerarias de adobes o en tumbas en forma de bota (Donnan 1995). Se trataba de sepulturas individuales, dobles, múltiples o colectivas. Los difuntos estuvieron tradicionalmente enterrados en decúbito dorsal, los brazos extendidos a lo largo del cuerpo, con una orientación Norte-Sur, con la cabeza al sur, con ligeras variaciones en la posición del cuerpo y, en algunos casos, en posición fetal. Antes de ser enterrados, los cadáveres recibían un tratamiento mortuorio complejo, registrándose hasta siete tipos 


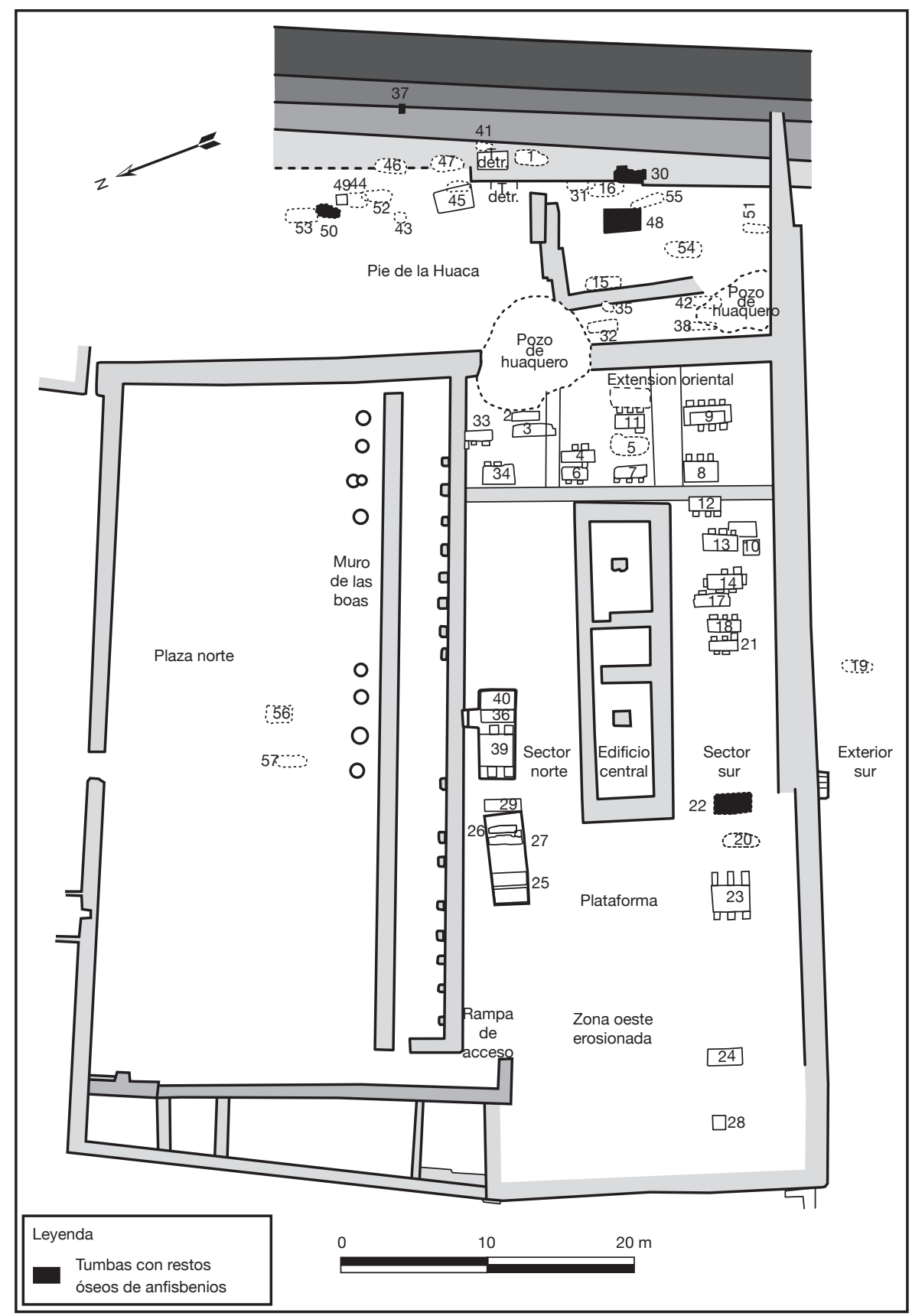

Fig. 2. - Plano de la Plataforma Uhle con la ubicación de las tumbas que contenían restos óseos de anfisbénidos (Programa Internacional Moche). 
TABLA 1. - Registro de anfisbenios en las tumbas de la Plataforma Uhle. Moche III : 200/250 à 450 d. C. Moche IV : 450 à $600 / 650$ d. C.

\begin{tabular}{|c|c|c|c|c|c|}
\hline Tumba & $\begin{array}{c}\text { Filiación } \\
\text { estilística } \\
\text { (Larco 1948) }\end{array}$ & & $\begin{array}{l}\text { ocalización de los restos } \\
\text { óseos de anfisbenios }\end{array}$ & $\begin{array}{l}\text { Partes } \\
\text { anatómicas }\end{array}$ & $\begin{array}{l}\text { Número Minimo de } \\
\text { Individuos (N.M.I.) }\end{array}$ \\
\hline \multirow[t]{2}{*}{22} & Moche IV & $\begin{array}{l}\text { Esquina } \\
\text { nor-este }\end{array}$ & $\begin{array}{l}\text { Botella asa estribo con una deco- } \\
\text { ración de flores }\end{array}$ & $\begin{array}{l}\text { cráneo, vertébras y } \\
\text { costillas }\end{array}$ & 1 \\
\hline & & Total & & & 1 \\
\hline \multirow[t]{5}{*}{30} & Moche III & $\begin{array}{l}\text { Hornacina } \\
\text { nor-este }\end{array}$ & $\begin{array}{l}\text { Cántaro con decoración pintada } \\
\text { de diseños geométricos (escalo- } \\
\text { nados, círculos, olas, puntos) }\end{array}$ & $\begin{array}{l}\text { cráneos, vertébras y } \\
\text { costillas }\end{array}$ & 10 \\
\hline & & & $\begin{array}{l}\text { Cántaro con decoración en relieve } \\
\text { de cuatro lagartijas (cañanes) sep- } \\
\text { arados en paneles }\end{array}$ & $\begin{array}{l}\text { cráneos, vertébras y } \\
\text { costillas }\end{array}$ & 2 \\
\hline & & $\begin{array}{l}\text { Hornacina } \\
\text { sur }\end{array}$ & $\begin{array}{l}\text { Cántaro con decoración en relieve } \\
\text { de cuatro lagartijas (cañanes) sep- } \\
\text { arados en paneles }\end{array}$ & vertébras & 1 \\
\hline & & $\begin{array}{l}\text { Esquina } \\
\text { sur-oeste }\end{array}$ & $\begin{array}{l}\text { Cerca del cráneo del individuo } \\
\text { adulto, bajo la mascara de cobre }\end{array}$ & $\begin{array}{l}\text { Esqueleto completo } \\
\text { en conexion }\end{array}$ & 1 \\
\hline & & Total & & & 14 \\
\hline \multirow[t]{2}{*}{37} & Moche III & $\begin{array}{l}\text { Esquina } \\
\text { nor-oeste }\end{array}$ & $\begin{array}{l}\text { Cántaro de cuerpo oblongo con } \\
\text { decoración radial triangular }\end{array}$ & $\begin{array}{l}\text { Esqueleto completo } \\
\text { en conexion }\end{array}$ & 1 \\
\hline & & Total & & & 1 \\
\hline \multirow[t]{2}{*}{48} & Moche III & $\begin{array}{l}\text { Esquina } \\
\text { sur-este }\end{array}$ & $\begin{array}{l}\text { Cántaro con decoración } \\
\text { de círculos incisos }\end{array}$ & $\begin{array}{l}\text { cráneos, vertébras y } \\
\text { costillas }\end{array}$ & 1 \\
\hline & & Total & & & 1 \\
\hline \multirow[t]{2}{*}{$50 \mathrm{a}$} & Moche III & $\begin{array}{l}\text { Esquina } \\
\text { sur }\end{array}$ & $\begin{array}{l}\text { Cántaro con decoración pintada } \\
\text { de dos felinos lunar }\end{array}$ & $\begin{array}{l}\text { cráneos, vertébras y } \\
\text { costillas }\end{array}$ & 3 \\
\hline & & Total & & & 3 \\
\hline
\end{tabular}

de envolturas funerarias que iban desde la mortaja hasta el ataúd de caña o de madera (Donnan 1995: 124-135). Los individuos podían ser acompañados de un importante ajuar funerario constituido por vasijas, ornamentos de metal, armas, herramientas, textiles, fauna, flora, etc.

\section{EL PAPEL DE LA FAUNA EN LAS TUMBAS MOCHICAS}

Las ofrendas animales formaron parte de los elementos depositados junto al difunto. Los análisis zooarqueológicos demostraron que se habían enterrado doce especies de animales en las tumbas mochicas (Goepfert 2008, 2010, 2011, 2012). Los animales frecuentemente depositados eran especies domésticas, y en particular camélidos: la llama (Lama glama) y la alpaca (Vicugna pacos) que fueron registrados en el 91\% de las tumbas que contenían restos faunísticos; también se enterraron perros (Canis familiaris) y conejillos de Indias o cuy (Cavia porcellus). La ofrenda de especies salvajes era escasa. Por ejemplo, se encontró un murciélago vampiro (Desmodus rotundus), un alcaraván o huerequeque (Burbinus superciliaris) y loros (Ara militaris y Amazona sp.).

Los reptiles jugaron un papel limitado dentro de los rituales mochicas. En realidad, solo se registró el depósito de una "serpiente" en Sipán (Alva \& Donnan 1993: 59; Alva 2004: 127). Este espécimen fue depositado en el ataúd de un niño en la tumba 2. No se analizaron los restos óseos de esta "serpiente" 


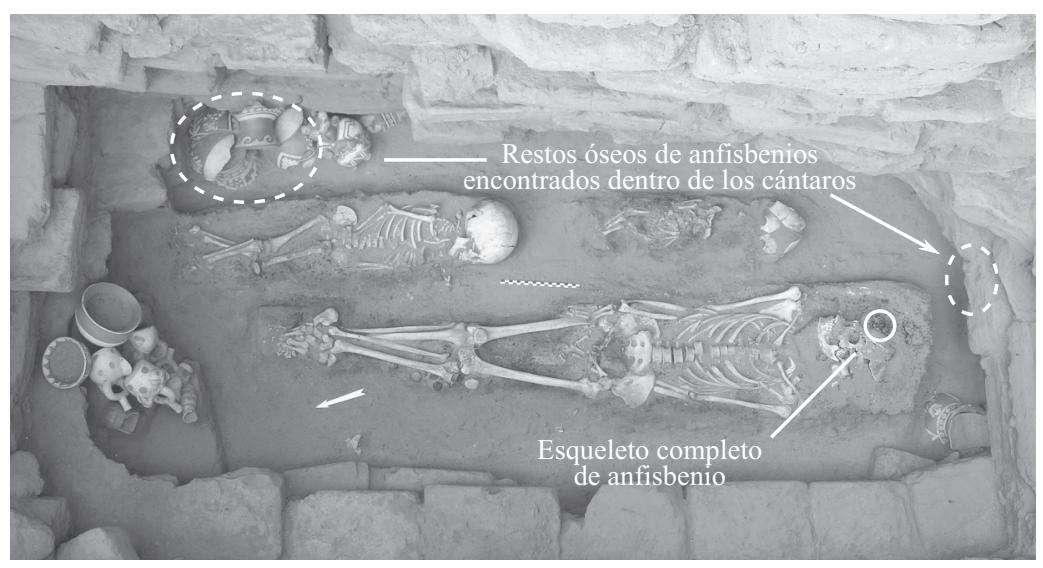

Fig. 3. - Vista general de la tumba 30 y ubicación de los anfisbenios (Programa Internacional Moche).

y la determinación taxonómica como tal debe ser revisada. El descubrimiento de restos de anfisbenios en cinco sepulturas de la Plataforma Uhle en el sitio de Huacas de Moche constituye un hallazgo singular que aporta nuevos datos sobre el papel de los reptiles en los rituales funerarios mochicas.

\section{LAS TUMBAS DE LA PLATAFORMA UHLE}

Cincuenta y siete tumbas, dentro de las cuales cinco contenían restos de reptiles (Tab. 1), fueron descubiertas por el Programa Internacional Moche. En este artículo presentamos los resultados del análisis de sólo dos contextos funerarios, las tumbas $30 \mathrm{y}$ 37 (Chauchat \& Gutiérrez 2006, 2007).

\section{LA TUMBA 30}

Exhumada al pie de la Huaca de la Luna, la tumba 30 es una de las más complejas de la Plataforma Uhle (Figs. 2, 3 y 4). Se trata de una cámara funeraria de adobes que contenía tres individuos: una mujer adulta, un niño de 1-5 años y un neonato de 3-6 meses que fueron enterrados en decúbito dorsal, cada uno dentro de un ataúd de caña. El ajuar funerario estaba compuesto de numerosas vasijas, una máscara de metal, collares, torteros (piruros) y diversos vestigios materiales (Chauchat \& Gutiérrez 2006: 103-113).

Durante la excavación de la sepultura, un esqueleto entero, en conexión anatómica, de

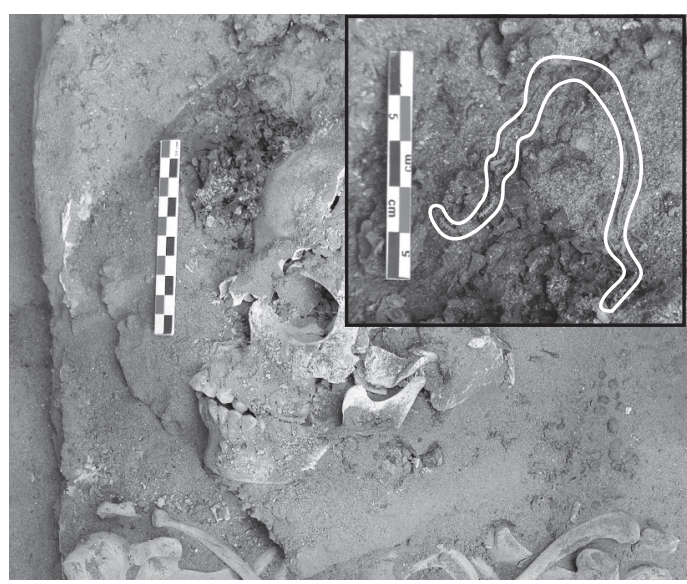

Fig. 4. - Esqueleto completo de un anfisbenios en la tumba 30 de la Plataforma Uhle (Programa Internacional Moche).

un anfisbenio fue descubierto en el ataúd de la difunta (Figs $3 \& 4$ ), cerca del cráneo, bajo un disco de cobre que cubría su rostro. Otros elementos óseos de anfisbenios se encontraron durante el tamizado del sedimento contenido en las vasijas depositadas en dos hornacinas realizadas en la base de la pirámide (Figs 3, $5 \& 6 \mathrm{~A}$ ). La cantidad de animales varía según los cántaros (Tab. 1): en la hornacina noreste, el primer cántaro contenía al menos diez individuos (Fig. 5A y 6A), el segundo dos individuos (Fig. 5-B), 

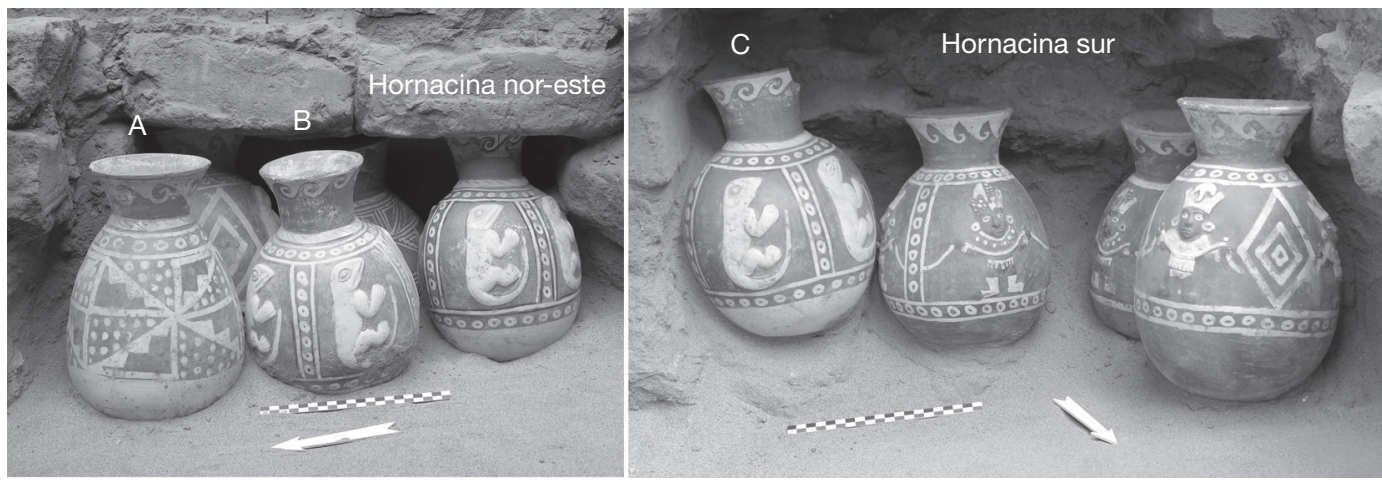

Fig. 5. - Hornacinas de la tumba 30 con los cántaros que contenían los restos óseos de anfisbenios (Programa Internacional Moche).

mientras que el cántaro ubicado en la hornacina sur sólo contenía un individuo (Fig. 5C).

\section{LA TUMBA 37}

La configuración de la tumba 37 es diferente a la anterior. Los dos individuos enterrados estuvieron cada uno envuelto en textiles y luego ambos formando un solo paquete o fardo funerario. Se trata de dos niños, uno de 4 años ( \pm 1 año) y un neonato de 3-6 meses. Su ajuar funerario se componía de dos collares de metal, dos vasijas y una pequeńa bolsa que contenía hojas de coca (Erythroxylon coca) (Chauchat \& Gutiérrez 2007: 61-63).

El esqueleto entero de un anfisbenio momificado (Fig. 6-B), se descubrió dentro del cántaro ubicado en la esquina noreste de la sepultura (Fig. 7). Todos estos elementos plantean obviamente el problema de la naturaleza antrópica o intrusiva del depósito de estos animales.

\section{LA IDENTIFICACIÓN TAXONÓMICA}

Sólo una parte de los segmentos occipitales e intermedios del cráneo, de las mandíbulas y de las vértebras colectadas en el primer cántaro de la tumba 30 pudo ser utilizada en el estudio taxonómico. A pesar de esto, su adscripción a Amphisbaenia no ofrece dudas (ver caracteres del grupo en Estes 1983; Gans \& Montero 2008; Kearney 2003).
La presencia de un ángulo cráneo-facial abierto (entre $160^{\circ}$ y $170^{\circ}$ ), de un rostro poco curvado ventralmente en vista lateral, de suturas fronto-parietales interdigitadas, de una sutura entre frontales ligeramente sinuosa, de un cóndilo occipital bilobulado en vista dorsal, de dientes subpleurodontos, de un proceso retroarticular reducido y orientado posteriormente y de vértebras con un arco neural liso y ligeramente cóncavo posteriormente permiten atribuir el material a un representante del género Amphisbaena (Albino \& Kligmann 2009; Gans \& Montero 2008).

Entre los segmentos occipitales estudiados, dos tipos morfológicos son observables: un primer tipo (morfotipo 1) caracterizado por la presencia de procesos paraoccipitales bien individualizados y que ocupan una posición relativamente posterior $y$, en vista ventral, de elementos-X bien desarrollados y que constituyen dos protuberancias ventrales bien visibles en norma posterior (Fig. 8), y un segundo tipo (morfotipo 2), en el que los procesos paraoccipitales aparecen más redondeados y menos individualizados, la cresta occipital posee un contorno más circular y los elementos-X están menos desarrollados (Fig. 8).

Para estudiar estos restos, recolectamos siete ejemplares de Amphisbaena occidentalis occidentalis (Fig. 9) en la Campińa de Moche, cerca del sitio arqueológico, y que junto con la subespecie $A$. $o$. townsendi son los únicos anfisbénidos actualmente presentes en la costa peruana (Carillo \& Icochea 


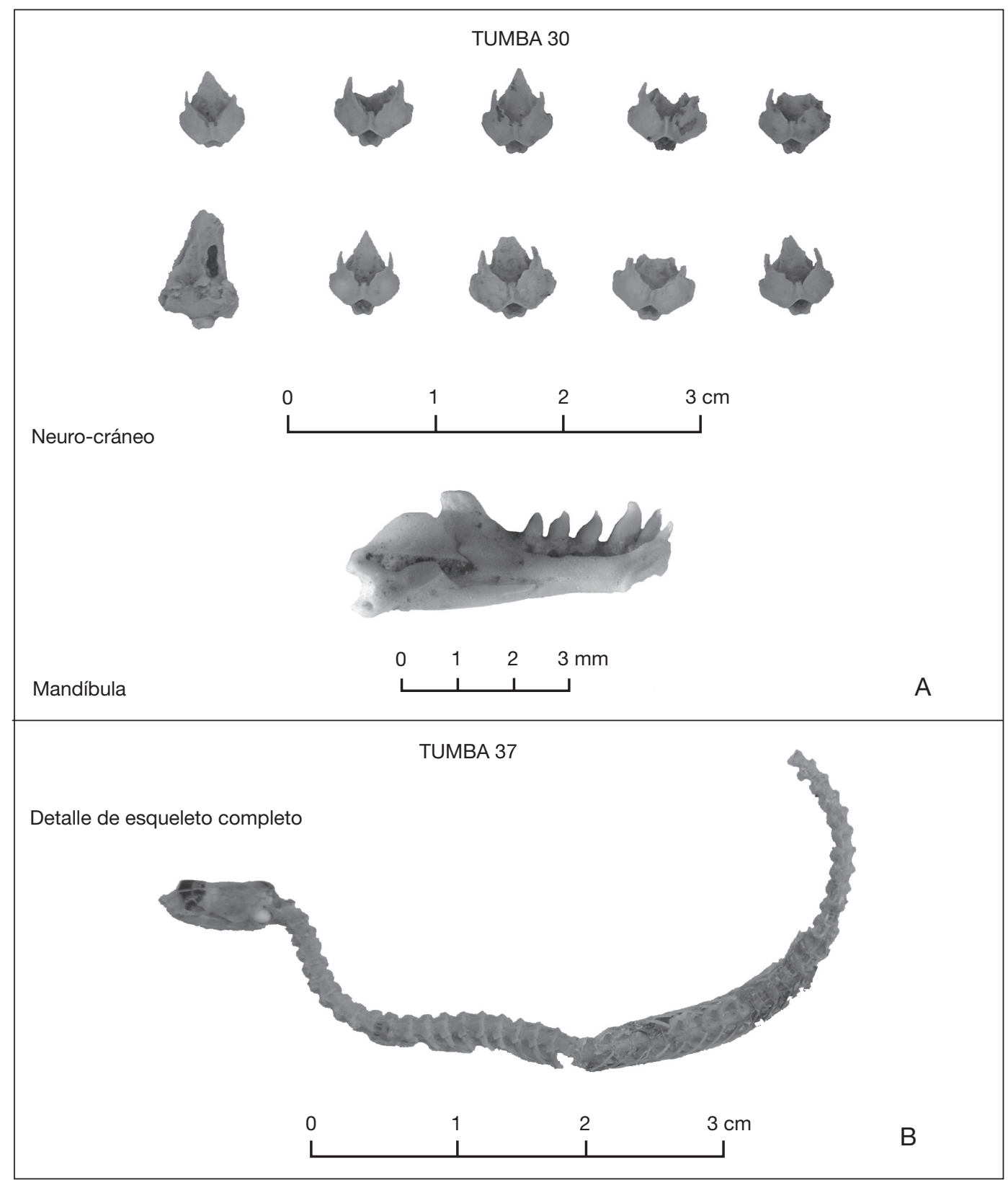

Fig. 6. - Detalle de los restos óseos de anfisbenios encontrados en las tumbas 30 y 37 de la Plataforma Uhle (Fotos : N. Goepfert y C. Lefèvre).

1995; Gans 1961). Cuatro de ellos han sido preparados desde el punto de vista osteológico y constatamos que el morfotipo 2 encontrado en la sepultura
30 corresponde a A. o. occidentalis, mientras que la asignación del morfotipo 1 queda en suspenso hasta un estudio más detallado y completo del material 


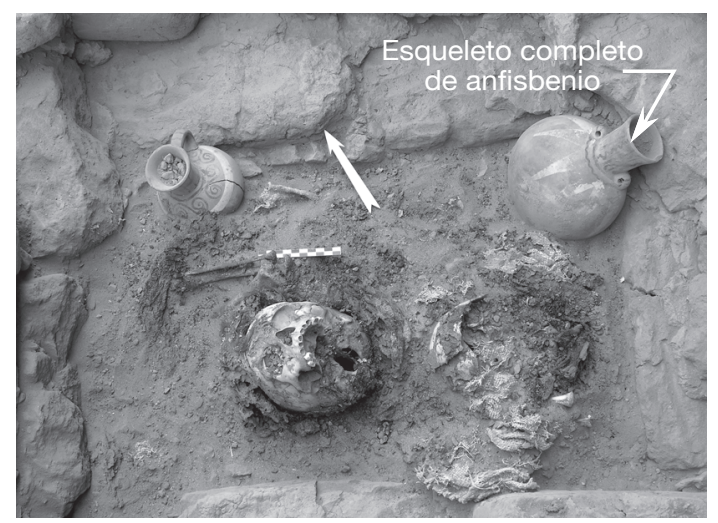

Fig. 7. - Vista de la tumba 37 con la ubicación del cántaro que contenía el esqueleto completo de un anfisbenios (Programa Internacional Moche).

fósil. Aunque estas diferencias morfológicas podrían atribuirse a cambios alométricos durante la ontogenia, como ha sido indicado para $A$. boliviana por Gans y Montero (2008), un estudio más completo del conjunto de material nos parece indispensable antes de proponer un resultado definitivo sobre su significado taxonómico.

El ejemplar colectado en la tumba 37 corresponde claramente a un individuo juvenil puesto que los elementos esqueléticos presentan una débil osificación.

\section{¿DEPÓSITOS FUNERARIOS O RESTOS INTRUSIVOS?}

El descubrimiento de restos de anfisbenios plantea obviamente numerosas preguntas y la primera trata sobre la naturaleza ritual o intrusiva de su depósito. Disponemos de varios elementos de carácter arqueológico y etológico que nos permiten afirmar que se trata efectivamente de depósitos funerarios intencionales.

En primer lugar, las sepulturas en las cuales se encontraron los anfisbenios están construidas de adobes y estaban completamente cubiertas y selladas. Su configuración hace que se asemejan a una verdadera cámara, limitando de hecho las intrusiones.

La tumba 30 de la Plataforma Uhle se construyó dentro de la fachada oeste de la Huaca de la Luna y su base descansaba sobre un suelo arenoso que constituiría quizá el único acceso posible para los anfisbenios. Es cierto que se trata de reptiles excavadores, pero no viven a profundidades superiores a los $25 \mathrm{~cm}$ bajo la superficie de la tierra, como pudimos observarlo durante la colecta de los especímenes actuales (Fig. 9). Además, se desplazan en tierra fértil muy diferente del sedimento arenoso del sitio arqueológico de Moche. Por ello, es poco probable que estos anfisbenios hayan cavado galerías a través de suelos en los cuales no acostumbran vivir. Esto es aún más evidente en la tumba 37, construida dentro de un escalón de la pirámide, que hace de ella un contexto mucho más hermético que el anterior. En esta tumba, no existe apertura posible para la entrada de los anfisbenios, lo que demostraría el depósito intencional por parte de los Mochicas.

La localización de los restos óseos dentro de los contextos funerarios presenta semejanzas que conviene explorar. En efecto, a excepción de un espécimen, los otros anfisbenios se encontraron dentro de cántaros depositados cerca del difunto. Se contaron hasta diez individuos en una vasija (Tab. 1) y es difícil considerar que estos animales hubieran cavado galerías a través de la cámara de las tumbas para venir a encerrarse, caer en gran número y "morir" dentro de las vasijas.

En conclusión, existen pocos elementos que corroboren una intrusión de estos animales y, al contrario, emitimos la hipótesis de un depósito ritual dentro de cántaros en varias tumbas.

\section{DATOS COMPARATIVOS}

Los depósitos funerarios de anfisbenios no son exclusivos de la cultura Mochica y depósitos similares son conocidos en el noroeste argentino.

Las primeras menciones de anfisbenios en contexto arqueológico provienen de los sitios de Shincal de Quimivil y Mesada de Carrizal (Capparelli \& Raffino 1997; Tobisch et al. 2005, ambas referencias citadas en Albino \& Kligmann 2009: 99-100), pero el descubrimiento más importante proviene del yacimiento de Tolombón. En este sitio fechado de 800-350 B.P., restos óseos pertenecientes a 21 individuos se encontraron en una urna funeraria 


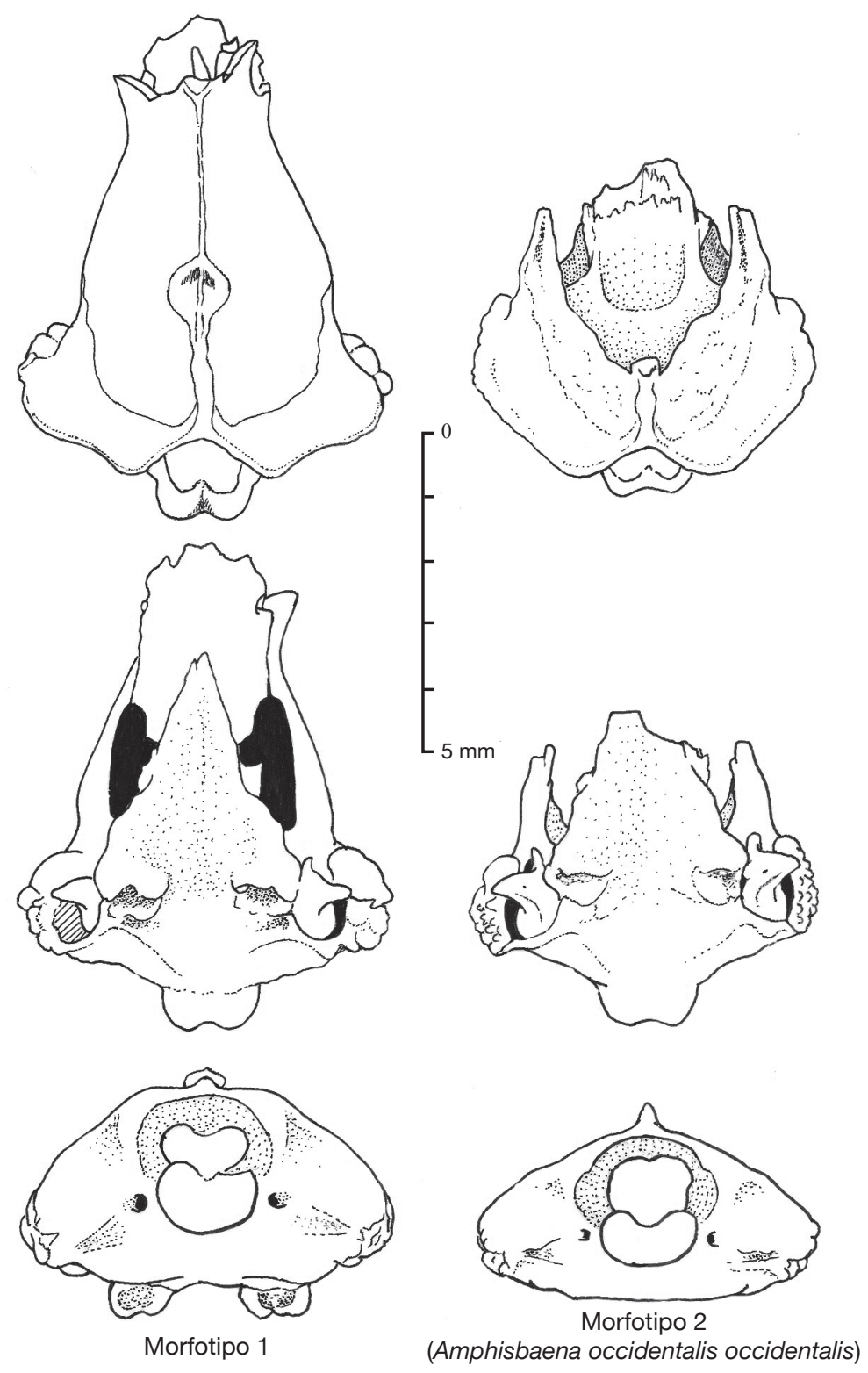

Fig. 8. - Dibujos de los dos morfotipos de neuro-cráneo de anfisbenios encontrados en las tumbas 30 y 37 de la Plataforma Uhle (Dibujo : S. Bailon).

(Ibid.: 100-101). El estudio taxonómico demostró que estos vestigios correspondían a la especie $\mathrm{Am}$ phisbaena heterozonata. Albino y Kligmann (2009: 103-105) asocian estas ofrendas a rituales vinculados a la estación de las lluvias, cuando los suelos se ceban de agua y los anfisbenios aparecen con más frecuencia. Durante el proceso de edición e impresión de nuestro artículo, Kligmann et al. (2013) publican 


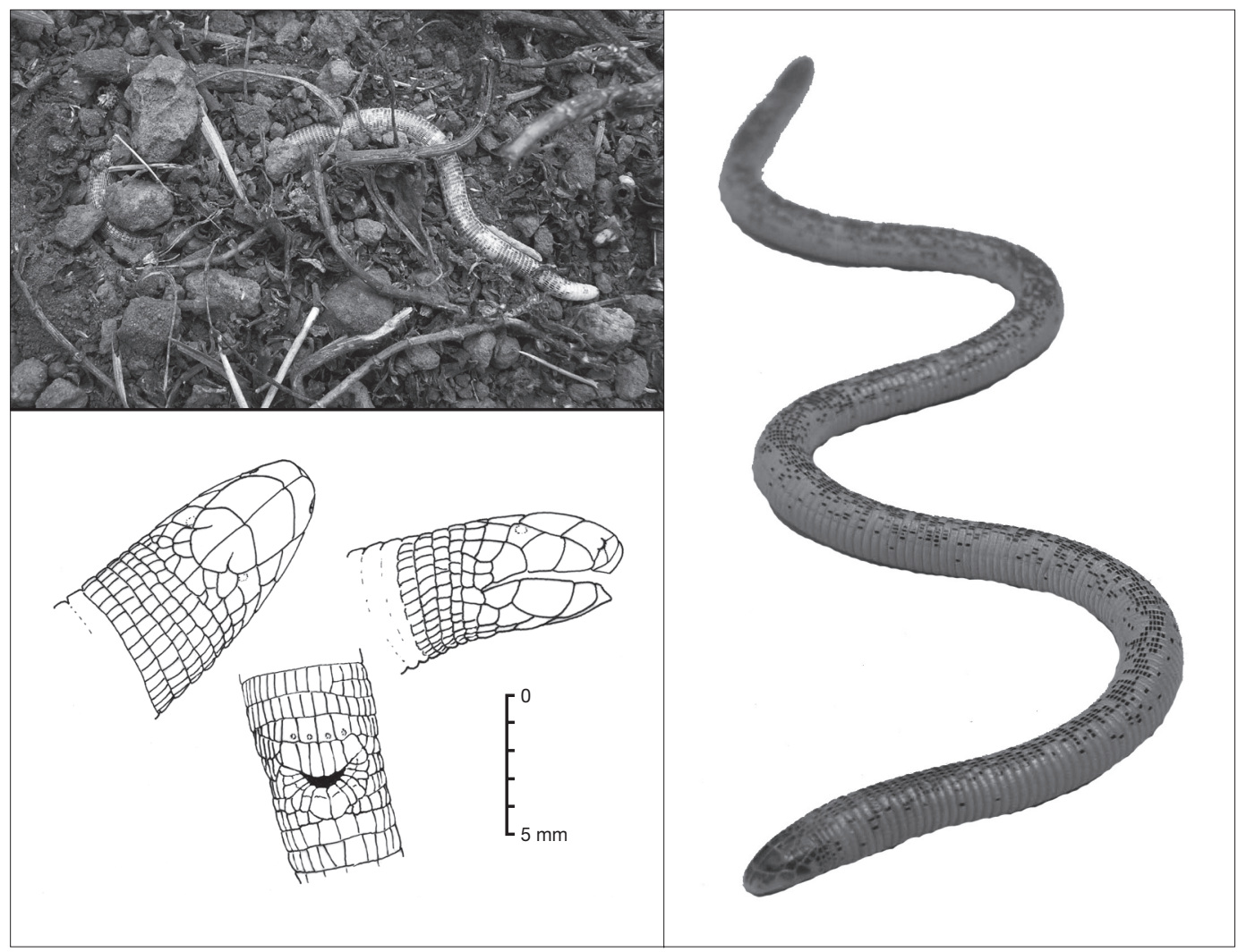

Fig. 9. - Espécimen actual de anfisbénido (Amphisbaena occidentalis occidentalis) (Dibujo : S. Bailon ; fotos : B. Gutiérrez y N. Goepfert)

un nuevo trabajo donde indican que las ofrendas de anfisbenios de Tolombón representarían una petición de lluvia a los dioses. Este simbolismo es interesante en el caso de culturas prehispánicas presentes en la Cordillera de los Andes, pero no adaptable stricto sensu a los contextos mochicas. En efecto, la pluviometría es bastante reducida y no existe temporada de lluvias en la costa peruana. Estas condiciones medioambientales sólo cambian en el momento de la aparición de El Niño, aunque la observación y la colecta de ejemplares actuales sin necesidad de esperar la lluvia hacen poco probable la vinculación entre estos depósitos mochicas y la manifestación de este fenómeno climático.

La asociación simbólica entre depósitos rituales y clima es un elemento que debe tenerse en cuenta en la comprensión general del simbolismo de estas ofrendas en el mundo andino. Consideramos que el depósito ritual de anfisbenios aparece como un fenómeno cultural no regional sino pan-andino conocido en varias épocas.

\section{LA ICONOGRAFÍA MOCHICA}

Para intentar comprender las razones de estos depósitos, la iconografía mochica puede aportar nuevos datos. La etimología del término anfisbenio significa que puede desplazarse en dos direcciones opuestas, del griego amphis, "dos vías" y bainein, "ir", entonces significa que "va en dos direcciones".

Se trata de pequeños reptiles, en su mayoría sin miembros, conocidos localmente (pero también en España) como "culebra de dos cabezas" o "culebra ciega”, por la semejanza entre la cabeza y la cola. Debido a su forma redondeada, estas dos partes pueden 


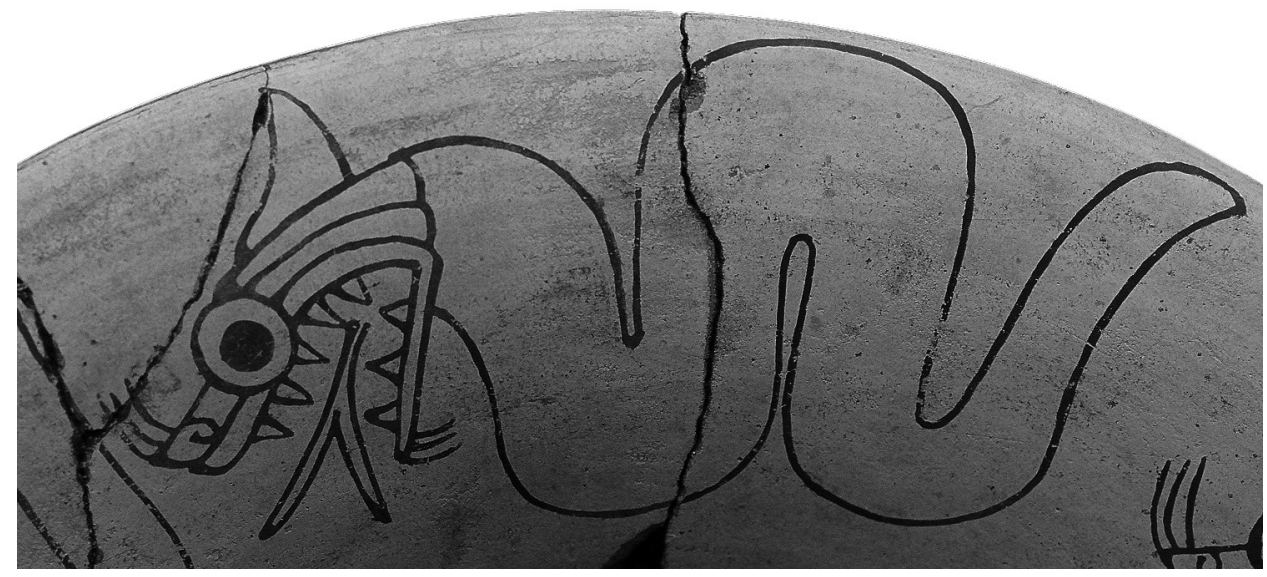

Fig. 10. - Animal hibrido presentando un cuerpo de serpiente y una cabeza de zorro. Motivo pintado en el cuerpo de un florero de la Plataforma Uhle (Programa Internacional Moche).

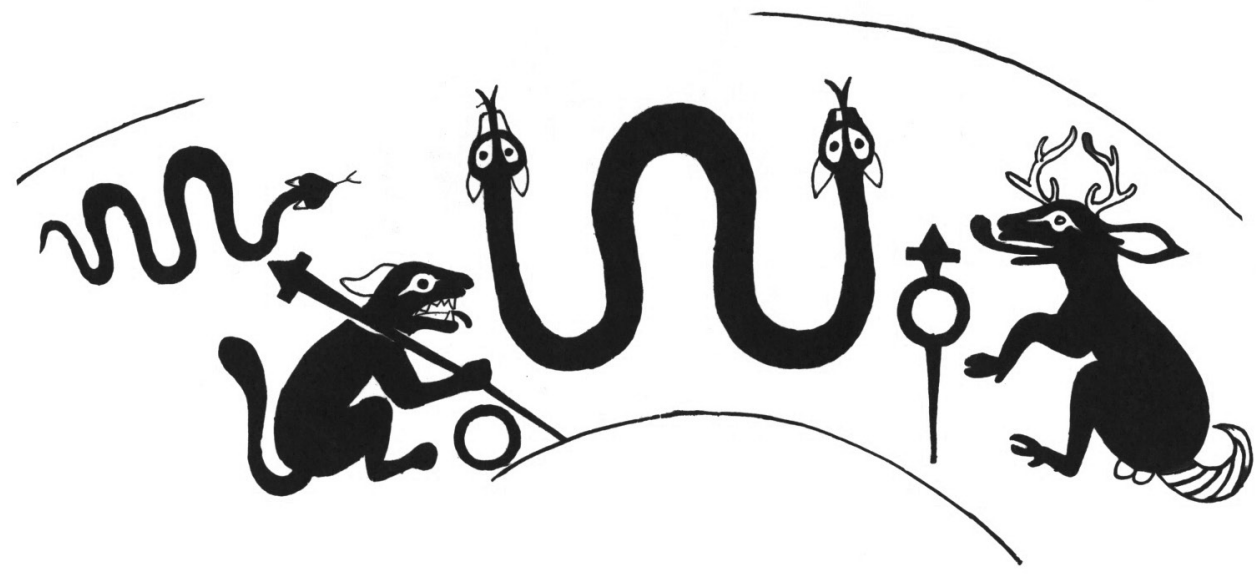

Fig. 11. - Representación de varios animales donde se diferencian dos serpientes: una con dos cabezas y la otra con una. Escena pintada en un florero; Musée Cernuschi Paris (Tomado de Kutscher 1983 : fig. 274).

confundirse a diferencia de las serpientes que, de una manera esquemática, tienen una cabeza más triangular. De este modo, la búsqueda de motivos serpentiformes de dos cabezas proporcionará tal vez nuevas informaciones sobre el simbolismo vinculado a estos animales. El registro iconográfico mochica presenta numerosas representaciones de reptiles, en particular de lagartijas, serpientes y serpientes de dos cabezas. Las lagartijas, los cañanes (Dicrodon holmbergi) están representados de manera antropomorfizada (Bourget 1994 vol. 2: 82) o realista (Bourget 1994 vol. 2: 82; Donnan \& McClelland 1999: 27, fig. 2.6; Kutscher 1983: fig. 19, 21; Lavallée 1970: 54 , pl. A, B y C), como los motivos en bajo-relieve 


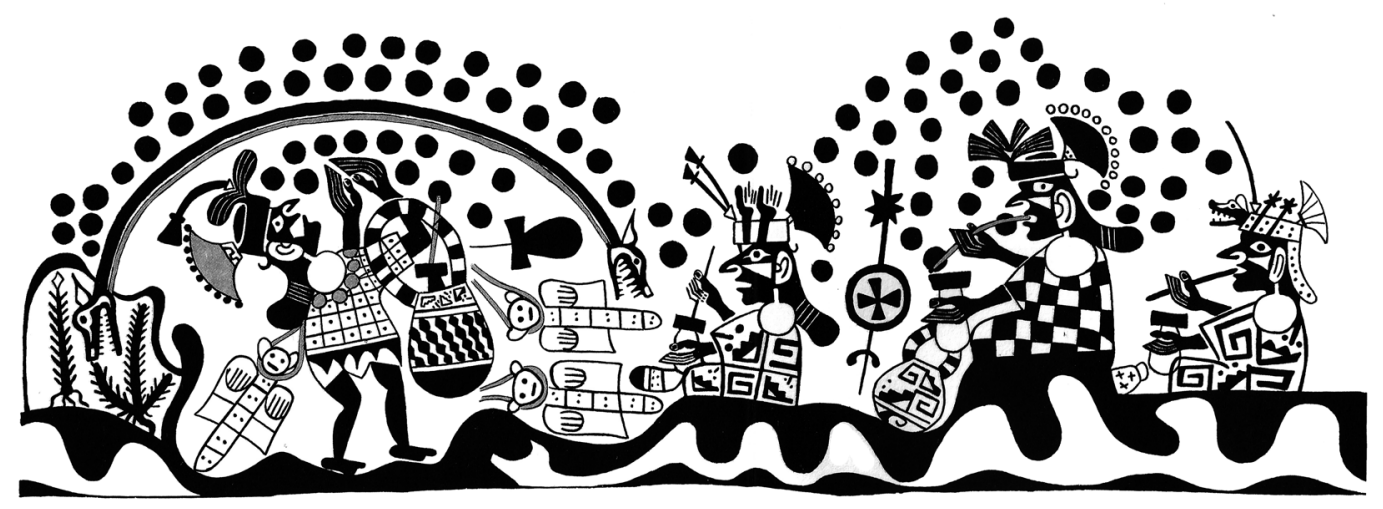

Fig. 12. - Serpiente de dos cabezas en forma de media luna sobre uno de los oficiantes. Escena pintada sobre el cuerpo de una botella asa-estribo; Linden-Museum, Stuttgart (Tomado de Kutscher 1983 : fig. 125).

de los cántaros de la tumba 30 (Fig. 5) donde se encontraron restos de anfisbenios. En cambio, las representaciones realistas de ofidios son bastante escasas (Bourget 1994: 140-142; Hocquenghem 1987: 204-208), la figura común en la iconografía mochica es la de un animal híbrido con un cuerpo de serpiente y una cabeza de zorro (Bourget 1994: 142-143; Hocquenghem 1987: 204-208; Lavallée 1970: 55, pl. 25), representada en forma escultórica o pintada sobre el cuerpo, las asas y el gollete de las vasijas (Fig. 10).

Hasta hoy día, no encontramos ninguna figura realista que represente un anfisbenio. No obstante, registramos varios dibujos de una "serpiente de dos cabezas", como el reproducido en la figura 11. Esta decoración, pintada sobre una vasija, representa dos serpientes, un venado y un zorro. Esta escena se organiza alrededor de una serpiente bicéfala: a su izquierda un zorro lleva una porra y se encuentra junto a una serpiente; a la derecha se sitúa un venado junto a un escudo y una porra. Aquí, dos reptiles rampantes están representados y comprobamos que los artistas mochicas distinguieron claramente una serpiente de una sola cabeza de otra bicéfala, sin que podamos asociar esta última claramente con un anfisbenio.

Este motivo aparece frecuentemente bajo una forma estilizada en escenas complejas de la iconografía mochica asociada a los ritos funerarios o sacrificiales. Por ejemplo, encontramos una ser- piente híbrida de dos cabezas en la "Ceremonia del Sacrificio" (Donnan y McClelland 1999: 131, fig. 4.102) donde separa los niveles superiores e inferiores de la escena. Otras serpientes bicéfalas se encuentran en el "Tema del Entierro" (Donnan y McClelland 1979, 1999: 276, fig. 6.152) donde figuran como sogas que sirvieron para bajar el ataúd del difunto. También está representada en forma de media luna ubicada en el cielo (Fig. 12). En esta escena, uno de los oficiantes se encuentra bajo una serpiente bicéfala, y los demás están sentados absorbiendo plantas psicotrópicas. Según Lavallée (1970: 109), esta serpiente bicéfala en forma de media luna simbolizaría la Vía Láctea y los puntos negros las estrellas.

La serpiente bicéfala es un motivo recurrente de la iconografía de las sociedades prehispánicas de los Andes centrales. Las primeras representaciones aparecen, por ejemplo, desde el Precerámico en el sitio de Huaca Prieta fechado en el 2500 a.C. y sobre los textiles Paracas (800-200 a.C.). Según Bourget (1994: 142), se encuentra en particular en las culturas Chavín, Cupisnique y Paracas, en los cuales está asociado al concepto de poder y de religión. Según Hocquenghem (1987: 208), la presencia de los colmillos - atributo de los ancestros -, simbolizaría la fuerza y la inmortalidad de las huacas (o wakas, es decir lugares sagrados, divinidades protectoras u objetos poseedores de una "fuerza animante" y fecundadora), y por extensión 
al poder de los ancestros. Se encuentra también en las vasijas de numerosas culturas de la costa norte de Perú y, más tarde, sobre las paredes del templo chimú en la Huaca del Dragón. Asimismo, otras iconografías prehispánicas presentan numerosas serpientes bicéfalas, como en la cultura Aguada en Argentina (Kligmann \& Díaz 2007). De manera general, en las creencias andinas, la serpiente de dos cabezas es llamada amaru y representa el arco iris de día y la Vía Láctea de noche (Urton 1981: 179).

La contribución de la iconografía mochica es paradójica. Proporciona numerosas representaciones estilizadas de una serpiente bicéfala, pero no incluye ningún motivo realista de anfisbenios. No obstante, serpientes híbridas de una y dos cabezas pueden cohabitar en la misma escena (Fig. 11), mostrando claramente la voluntad de los artistas mochicas de diferenciarlos. No se puede descartar el hecho de que este tipo de motivo bicéfalo represente el dualismo, concepto tan presente en la zona andina. Entonces, esas figuras serían simplemente un desdoblamiento simétrico de un mismo motivo, como lo muestra Lévi-Strauss (1958: 278-320) para otras culturas. En ese caso, esta serpiente bicéfala sería el reflejo duplicado de una serpiente de una cabeza, limitando nuestras interpretaciones.

\section{LAS FUENTES MÁS TARDÍAS}

\section{LOS DATOS ETNOHISTÓRICOS}

Fuentes escritas tardías aportan otros elementos de reflexión. En ese sentido, Duviols (1967: 23), transcribiendo un documento de Cristóbal de Albornoz del siglo XVI, indica que: "Hay otro género de guaca [waka o huaca] que es cierto género de culebra de diferentes hechuras. Las adoran y sirven. Tomaron los ingas prencipales sus apellidos. Nómbranse machacuay $y$ amaro. Estas, quando pueden ser havidas bivas, las meten en tinajas grandes y las sustentan muchos años con sangre de coyes y con yervas, y les hazen muchas fiestas y sacrificios.".

Como se puede observar, algunas culebras fueron consideradas como huacas, conservadas en tinajas y alimentadas con sangre de cuyes (conejillo de Indias) y yerbas. Aunque no se pueda definir con precisión de qué tipo de "serpiente" está hablando este cronista - los nombran machacuay y amaro -, el hecho de encontrarlos en tinajas recuerda el depósito de anfisbenios en los cántaros de las sepulturas de la Plataforma Uhle en Moche y del sitio de Tolombón en Argentina.

Pero volvamos un instante sobre este pasaje y sobre la presencia de las "serpientes" machacuay y amaro. Si el primer término es la palabra quechua para hablar de las serpientes, el segundo se asocia posiblemente a la serpiente bicéfala de la mitología andina. Nombrando así a estos reptiles, Cristóbal de Albornoz utiliza quizá el término de amaru para referirse a una serpiente de dos cabezas y, en consecuencia, para diferenciarla de la de una sola cabeza. ¿Haría así referencia a los anfisbenios? Podemos sugerirlo pero no afirmarlo.

En los Andes, tal como ocurre con los batracios, las serpientes simbolizan la alternancia de las estaciones, el culto agrario, el culto al agua y la fertilidad (Bouysse-Cassagne 1988: 90, 92-94; Urton 1981: 179). Al inicio de las lluvias, surgen del mundo subterráneo y simbolizan una doble migración: una entre las estaciones secas y húmedas, otra entre el inframundo y la tierra. La serpiente sagrada, mach'ácuay, se encuentra en la Vía Láctea (Urton 1981: 177-179), siendo un importante mediador entre el mundo celestial, la residencia de los muertos y las paqarinas, los lugares de creación. Su encarnación metafórica toma también la forma de una serpiente bicéfala (Urton 1981: 93). Estos reptiles aún continúan siendo un objeto de culto, en particular durante el Carnaval de Oruro en Bolivia que se percibe como un pachacuti, es decir un período de inversión del orden normal (Bouysse-Casssagne 1988: 102, 163-171), como podría haber sido el mundo de los muertos para los Mochicas (Benson 1975; Bourget 2006).

El amaru, como serpiente bicéfala, es un símbolo que se encuentra en toda el área andina. En efecto, está vinculado al arco iris y a la Vía Láctea. Para entender lo que los une, es necesario revisar como se manifiesta en las creencias populares. Urton (2006: 101) destaca que "Los arco iris son especialmente importantes en este sentido, porque son concebidos como serpientes gigantes que emergen desde manantes y fuentes subterráneas, se desplazan a través del cielo y enclavan una de sus dos cabezas 
en una fuente distante". El arco iris está entonces percibido como una serpiente gigante de dos cabezas que, según esta creencia, relaciona al cielo con el vientre de las montańas, donde se encuentran las paqarinas (Urton 1981: 93). Urton asocia este fenómeno meteorológico al cósmico, en este caso la Vía Láctea, ya que ésta prosigue su camino bajo tierra. Esta última se relaciona a las manifestaciones subterráneas y conecta el mundo de los muertos a la esfera celestial.

Urton (2006: 193) menciona también el simbolismo vinculado a las estaciones cuando escribe: "Debido a que los serpientes meteorológicos (Arco Iris) Amarus) emergen solamente durante la estación lluviosa del año, exhiben una actividad estacional similar a la de los reptiles terrestres". Existe entonces una estrecha relación entre la serpiente bicéfala llamada amaru, la alternancia de las estaciones y el culto al agua. Los reptiles (serpientes y lagartijas) están simbólicamente considerados como agentes mediadores entre el mundo subterráneo, la superficie de la tierra y, por extensión, el mundo celestial. En su trabajo sobre la iconografía mochica, Lavallée (1970: 109) relaciona la serpiente de dos cabezas con la lluvia, la Vía Láctea, la fecundación de la tierra, las enfermedades y los seres deformes. Todos estos elementos son interesantes pero es necesario tener cuidado porque el ciclo vital de las especies costeńas difiere de las que viven en la sierra. Además, las condiciones climáticas y medioambientales son distintas y la alternancia de las estaciones es menos marcada en la costa.

El arco iris, fenómeno meteorológico diurno, asimilado a la serpiente bicéfala, se transforma durante la noche en Vía Láctea. El paralelo establecido entre la entidad terrestre y su doble cósmico sugiere quizá que la serpiente y el anfisbenio sean avatares terrestres del machácuay y del amaru, lo que podría explicar su presencia en vasijas mochicas e incas.

Obviamente, la comparación directa es imposible pero es sorprendente encontrar el mismo tipo de depósito en la cultura Mochica de la costa norte del Perú entre 100 y 800 d.C, en el sitio de Tolombón en el noroeste argentino entre 1100 y $1600 \mathrm{~d}$. C. y en el pasaje citado de la crónica de Cristóbal de Albornoz que trata de las creencias religiosas incas. Estas evidencias pertenecen a culturas distantes en cientos de ańos que vivieron en regiones alejadas de varios millares de kilómetros. El paralelo puede ser establecido pero ¿Se trataba de los mismos animales? ¿Era el mismo tipo de depósito? ¿Eran rituales similares? ¿El término amaro/amaru aquí citado corresponde al anfisbenio? Sólo futuros descubrimientos permitirán saber más y definir con claridad este singular hallazgo.

\section{LOS TESTIMONIOS ETNOGRÁFICOS}

Los anfisbenios integran los mitos y creencias de las poblaciones amazónicas. En un mito Miraña (Colombia) que menciona D. Karadimas, los anfisbenios juegan el papel de comida mortuaria ${ }^{1}$. La función simbólica aquí asignada a los anfisbenios procede de una región totalmente diferente a la de los Mochicas, pero la utilización de estos especímenes como alimento de los muertos nos remite directamente a los contextos funerarios mochicas. ¿Estos animales, colocados en vasijas, desempeńaban un papel similar? Nada permite afirmarlo pero es necesario seguir las investigaciones para comprender el vínculo entre depósito funerario y alimentación mortuoria.

\section{CONCLUSIÓN Y PERSPECTIVAS}

Finalmente, el estudio taxonómico de estos restos demostró que estamos en presencia de dos morfotipos de cráneos: uno asignado a Amphisbaena occidentalis occidentalis, la única especie costeña registrada, y otro que correspondería probablemente a una variación alométrica y no necesariamente a otro taxón.

El hallazgo y la identificación de anfisbenios en sepulturas mochicas es algo único y es la primera

1 "los anfisbenios están considerados como la comida de los muertos. Este mito relata la visita de un espectro a su antigua mujer. En su encuentro, quiere ofrecerle larvas de palmitos (uno de los platos favoritos de los Indios de la región), pero le presenta anfisbenios que le disgustan. Ésta, por temor a herir a su marido difunto y causar su ira, no se atreve a comunicarle su aversión, y le hace creer que no tiene hambre. Ante este equívoco, ella se da cuenta que es el espectro de su marido y no su verdadero esposo, puesto que le ofrece anfisbenios en lugar de larvas". (Com. pers. D. Karadimas, Cnrs-Laboratorio de Antropología Social, mayo de 2008). 
mención de este tipo de depósitos en esta cultura, pero también en las de la vertiente occidental de los Andes. Anteriormente, en sólo un depósito del noroeste argentino se habían registrado estos animales en contextos funerarios. No se trata de un fenómeno aislado, sino de un proceso multicultural y de larga duración temporal presente en el área andina. ¿Cómo explicar estas ofrendas? Como vimos, estos depósitos estuvieron posiblemente vinculados al inframundo, las lluvias y a la alimentación de los muertos. El estudio del registro iconográfico mochica no proporciona representaciones realistas de los anfisbenios. Sin embargo, existen numerosas figuras estilizadas de serpientes de dos cabezas pero nada permite afirmar que se trata efectivamente de anfisbenios.

Disponemos de pocos datos para responder con precisión a todas las preguntas planteadas. Será necesario, en el futuro, estudiar toda la colección procedente de las tumbas mochicas para tener un mejor sustento de la recurrencia de estos depósitos. También se necesitará recopilar información de las representaciones de serpientes de dos cabezas en las otras culturas prehispánicas para comprender mejor su simbolismo y las razones de su depósito funerario en toda el área andina.

\section{Agradecimientos}

Agradecemos a S. Lepetz y R.-M. Arbogast, los organizadores de la sesión "The animal in funerary practices" del congreso 2010 del ICAZ, por permitirnos presentar por primera vez los resultados de este trabajo. Agradecemos a Claude Chauchat, director del Programa Internacional Moche, por autorizarnos estudiar el material óseo de la Plataforma Uhle. Muchas gracias también al Sr. Jorge Caballero quien supo ubicar muy precisamente, en los campos de cultivos de la Campiña de Moche, los lugares donde se encontraban los anfisbenios necesarios a nuestro estudio taxonómico. Agradecemos también a las manos expertas de Eric Pellé (MNHN) quien nos ayudó a preparar dichos especímenes actuales. Gracias a Anthony Herrel (CNRS, UMR
7179) por las determinaciones taxonómicas de los anfisbenios y sus comentarios sobre la etología de estas especies.

\section{REFERENCIAS}

Albino A. M. \& Kligmann D. M. 2009. - Inusual hallazgo de anfisbénidos (Squamata, Amphisbaenidae) en un yacimiento arqueológico de Argentina. Revista Española de Herpetología 23: 99-106

Alva W. 2004 - Sipán. Descubrimiento e investigación, Edición del autor, Lima.

Alva W. \& Donnan C. B. 1993 - Royal Tombs of Sipán, Fowler Museum of Cultural History-Universzity of California, Los Angeles.

Benson E. P. 1975 - Death-Associated Figures on Mochica Pottery, in Benson E. (éd.), Death and Afterlife in Pre-Columbian America. A conference at Dumbarton Oaks (October 27th, 1973), Dumbarton Oaks Research Library and Collections, Washington: 105-144.

BOURGET S. 1994 - Bestiaire sacré et flore magique: écologie rituelle de la culture Mochica, côte nord du Pérou. PhD en Anthropologie, Université de Montréal, Montréal.

BOURGET S. 2006 - Sex, death, and sacrifice in Moche religion and visual culture, University of Texas Press, Austin.

BOUYSSE-CASSAGNE T. (avec la collaboration de P. BOUYSSE) 1988 - Lluvias y Cenizas. Dos Pachacuti en la Historia, Hisbol, La Paz.

Capparelli A. \& RAFFino R. 1997 - Arqueoetnobotánica de El Shincal I: Tallos finos, frutos y semillas. Tawantinsuyu 3: 40-57.

Carillo de Espinoza N. \& ICOChea J. 1995 - Lista taxonómica preliminar de los reptiles vivientes del Perú. Publicaciones del Museo de Historia Natural (UNMSM), Serie A Zoología 49: 1-27.

Castillo L. J. 2000. — Los rituales mochica de la muerte, in Krzysztof Makowski (éd.), Los dioses del antiguo Perú, Banco del Credito, Lima: 103-135.

Chapdelaine C. 2001. - The Growing Power of a Moche Urban Class, in J. Pillsbury (éd.), Moche Art and Archaeology, National Gallery of Art, New Haven and London: Distributed by Yale University, Washington: 69-87.

Chauchat C. 2000. — Grande cité de Moche. Découvertes dans la mystérieuse. Archeologia 368: 32-41.

CHAUCHAT C. \& GUTIÉRREZ B. 2006. - Excavaciones en la Plataforma Uhle, in UCEDA S. \& Morales R.(éds.), Informe técnico 2005. Proyecto Arqueológico Huaca de la Luna, Facultad de Ciencias Sociales-Universidad Nacional de La Libertad-Backus-Fundación Wilson, Trujillo: 81-135.

ChAUCHAT C. \& GUTIÉRREZ B. 2007. — Excavaciones en la Plataforma Uhle, in S. Uceda \& R. Morales (éds.), 
Informe técnico 2006. Proyecto Arqueológico Huaca de la Luna, Facultad de Ciencias Sociales-Universidad Nacional de La Libertad-Backus-Fundación Wilson, Trujillo: 47-87.

Chauchat C., Gutiérrez B., Deverly D. \& GoepFERT N. 2008. — Recherches sur l'élite de la société Mochica. La plateforme Uhle à Moché, sur la côte nord du Pérou. Les Nouvelles de l'Archéologie 111112: 116-122.

Chauchat C., Gutiérrez B., Deverly D., Goepfert N. \& HucheT J.-B. 2009. — La Plataforme Uhle en Moche. Una síntesis de los descubrimientos. Revista del Museo de Arqueología, Antropología e Historia de Trujillo 11: 85-110.

Chauchat C., Wing E., Lacombe J.-P., Demars P.-Y., UCEDA S. \& Deza C. 1992. - Préhistoire de la Côte Nord du Pérou: le Paijanien de Cupisnique, Cahiers du Quaternaire 18, CNRS Éditions, Paris.

Chauchat C., Wing E., Lacombe J.-P., Demars P.-Y., UCEDA S. \& DeZa C. 2006. - Prehistoria de la costa norte del Peru. El Paijanense de Cupisnique, Travaux de l'Institut Français d'Etudes Andines (IFEA), tome 211, IFEA-Patronato Huacas del valle de Moche, Lima.

Donnan C. B. 1995. - Moche Funerary Practices, in Dillehay T. (éd.), Tombs for the Living: Andean Mortuary Practices. A Symposium at Dumbarton Oaks, $12^{\text {th }}$ and 13 th October 1991, Dumbarton Oaks Research Library and Collection, Washington D.C.: 111-159.

Donnan C. B. 2010. - Moche State Religion. A Unifying Force in Moche Political Organization, in QUILTER J. \& CASTILlO L. J. (éds.), New perspectives on Moche political organization, Dumbarton Oaks Research Library and Collection, Washington D.C.: 47-69.

Donnan C. B. \& MaCKeY C.J. 1978. - Ancient Burial Patterns of the Moche Valley, University of Texas Press, Austin et London.

Donnan C. B. \& McClelland D. 1979. - The Burial Theme in Moche iconography, Studies in PreColumbian Art and Archaeology, 21, Dumbarton Oaks, Washington D.C.

Donnan C. B. \& MCClelland D. 1999. - Moche Fineline Painting. Its Evolution and Its Artists, UCLAFowler Museum of Cultural History, Los Angeles.

Duviols P. 1967. — Un inédit de Cristobál de Albornoz: La instrucción para descubrir todas las guacas del Pirú y sus camayos y haziendas. Journal de la Société des Américanistes 56-1: 7-39.

EsTES R. 1983. - Sauria Terrestria, Amphisbaenia. Handbuch der Paläoherpetologie, part 10a, Gustav Fischer Verlag, Stuttgart

Gans C. 1961. - Notes on Amphisbeanids (Amphisbaenia; Reptilia), Postilla Yale Peabody Museum of Natural History 56: 1-17

Gans C, MonTero R (2008). - An atlas of amphisbaenian skull anatomy. In Gans C, Gaunt AS, Adler K. editors. Biology of the Reptilia, Vol. 21, Morphology
I. The skull and appendicular locomotor apparatus of Lepidosauria. New Haven: Society for the Study of Amphibians and Reptiles: 621-738.

GOEPFERT N. 2008. — Ofrendas y sacrificio de animales en la cultura Mochica: el ejemplo de la Plataforma Uhle, Complejo Arqueológico Huacas del Sol y de la Luna, in L. J. Castillo Butters., H. Bernier, G. LOCKARD AND J. RuCABADO YONG (éds.), Arqueología Mochica. Nuevos Enfoques. Actas del Primer Congreso Internacional de Jóvenes Investigadores de la Cultura Mochica, Lima, 4-5 de agosto de 2004I, IFEA-Fondo Editorial de la PUCP, Lima: 231-244.

Goepfert N. 2010. — Llama and deer: food and symbolical dualism in the Central Andes area. Anthropozoologica 45(1): 25-45.

GOEPFERT N. 2011. - Frayer la route d'un monde inversé. Sacrifice et offrande animale dans la culture Mochica (100-800 apr. J.-C.), côte nord du Pérou. B.A.R. (British Archaeological Reports) International Series 2278, Archaeopress, Oxford.

GOEPFERT N. 2012. - New zooarchaeological and funerary perspectives on Mochica culture (A.D. 100-800), Peru. Journal of Field Archaeology 37 (2): 104-120.

Hocquenghem A.-M. 1987. - Iconografía Mochica, Fondo Editorial de la Pontificia Universidad Católica del Perú, Lima.

Kearney M. 2003. - Systematics of the Amphisbaenia (Lepidosauria: Squamata) based on Morphological Evidence from Recent and Fossil Forms. Herpetological Monographs 17: 1-74.

Kligmann D.M. \& Díaz País E. 2007. — Una primera aproximación a los motivos serpentiformes de la iconografía Aguada del NOA. Intersecciones en Antropología 8: 49-67.

Kuigmann D.M., Albino A.M. \& Díaz País E. 2013. Anfisbenas para los dioses: zooarqueología de una ofrenda animal, in IZETA A. D. \& MENGONI GOÑALONS G. L. (ed.), De la Puna a las Sierras: avances y perspectivas en zooarqueología andina, BAR International Series 2564, Oxford: 89-119.

KuTSCHER G. 1983. - Nordperuanische Gefämalerein des Moche-Stils, Materialen zur Allgemeinen und Vergleichenden Archäologie, Band 18, Verlag C. H. Beck, Munich.

Larco Hoyle R. 1938. - Los Mochicas. Tomo 1, Casa editora La Crónica y Variedades S. A., Lima.

Larco Hoyle R. 1939. - Los Mochicas. Tomo 2, Casa editora La Crónica y Variedades S. A., Lima.

LAVALLÉE D. 1970. - Les représentations animales dans la céramique Mochica. Mémoires de l'Institut d'Ethnologie 4, Université de Paris, Paris.

Lavallée D., Julien M., Béarez P., Usselmann P., Fontugne M. \& Bolaños A. 1999. - Pescadoresrecolectores arcaicos del extremo sur peruano. Excavaciones en La Quebrada de los burros (Tacna, Perú). Primeros resultados 1995-1997. Bulletin de l'Institut 
Français d'Études Andines (IFEA) 28 (1): 13-52.

LÉvi-STRAuss C. 1958. - Anthropologie structurale, Plon, Paris.

Millaire J.-F. 2002. — Moche burial patterns: An investigation into Prehispanic social structure, B.A.R. (British Archaeological Reports) International Series 1066, Oxford.

Quilter J. \& L. J. Castillo 2010. - New Perspectives on Moche Political Organization. Dumbarton Oaks Research Library and Collections, Washington D. C..

Tobisch A., Padula G., Drube H. \& Salceda S. 2005. - Sitio de entierro múltiple en la Mesada de Carrizal, in Sempé C., Salceda S. \& Mafia M. (éds.), Azampay: Presente y Pasado de un Pueblito Catamarqueño. Antología de Estudios Antropológicos, Ediciones Al Margen, La Plata: 423-440.

UCEDA S. 2001. - Investigations at Huaca de la Luna, Moche valley: An example of Moche religious architecture, in J. Pillsbury (éd.), Moche Art and Archaeology, National Gallery of Art, New Haven and London: Distributed by Yale University, Washington: 47-67.

Uhle M. 1913. - Die Ruinen von Moche. Journal de la Société des Américanistes 10 (1): 95-117.

URTON G. 1981. - At the Crossroads of the Earth and the Sky. An Andean Cosmology, University of Texas Press, Austin.

URTON G. 2006. - En el cruce de rumbos de la Tierra y el Cielo, CBC, Cusco. 
